\title{
POSSIBILITIES OF MAINTENANCE IN FIELD CONDITIONS DESIGN
}

\author{
J. Furch \\ J. Glos \\ University of Defence, Brno, Czech Republic
}

\begin{abstract}
This paper introduces a container workshop project to perform the maintenance of The Czech Republic's land combat vehicles in field conditions. The presented workshop consists of two ISO IC size range containers with special equipment. The first container is called a "working unit" and the other one is a "special purpose unit". During combat activities the containers would be arranged in an $L$ shape with a rolled out roof. The article presents organizational and technical conditions connected with the implementation of the system of military equipment for temporary repairs for the military to ensure technical the support's functioning. Furthermore, the article mentions such issues as unification and the adjusting the equipment in the design and production processes, pro-active diagnostics, procedural conditionings, technology and temporary repair. Each issue is discussed considering possibilities and needs of the implementation of a temporary repair system.
\end{abstract}

Key words: logistics, operation system, field repairs of the military equipment, telemetry maintenance system, temporary repair, container workplace, battle damage repair kit, combat service support, maintenance of vehicles, field repair.

\section{Introduction}

The problem of unscheduled field repairs gains special importance in conditions of military operations during which the dominant source of equipment loss is combat and operational damage [1]. 
As the history and experiences of the last armed conflicts have shown, the enemy's use of modern agents of destruction is causing more and more military equipment losses [2]. In the case of an arming system, the significant part of the equipment damaged during combat operations is recovered and included in further operations thanks to its repair directly within the area of operations. This is a basic source of providing units with equipment; especially in the conditions of peace and stabilization missions [1,3].

The temporary repairs process is executed in field conditions and consists of the following stages:

- range of damage assessment,

- selection and elaboration of damage repair technology,

- making a decision concerning the repair providing that the repair can be done in an appropriate time period,

- execution of the repair in field conditions or having the damaged equipment repaired in a parent unit or in a repair plant.

To make this process fully effective and to make the executed repairs low-cost, easy to perform, and sufficiently durable, the requirements described in the following chapters should be met.

\section{Equipment Unification}

The complexity of modern military equipment means that in the scope of maintaining its operational readiness, a number of undertakings, not only of a technical nature, must be involved. One must remember that armament systems are technical objects that have specific requirements essential to the execution of their tasks [4].

Executing equipment for field repairs can be more or less complex and timeconsuming and in other words, it can be more or less expensive. Everything depends on the level of equipment preparation for the mentioned actions. That is, the equipment's susceptibility to field repair execution [4]. 
The susceptibility to temporary repairs is an ambiguous notion that is difficult to define. Undoubtedly, it is a component of maintainability, which is shaped mainly at the stage of constructing and producing an armament system.

The susceptibility to field repairs execution is a property of a device that describes its adaptation to repair work execution. The estimation of susceptibility to repair is high when an object is:

- designed keeping the modularity of assemblies,

- equipped with quick-mounting joints that provide quick assembly and disassembly.

- equipped with a possibility of using standard devices and tools in a process of assembly and disassembly,

- secured with base surfaces (openings) of the components in order to use them in a repair process,

- labelled in a way that enables easy and proper assembly of cooperative components of the object,

- constructed in a way that makes access to the most often damaged assemblies easy and, simultaneously, that enables easy mounting of damaged subassemblies or their repair without a necessity of disassembly,

- designed in a way that gives a possibility to use modern technologies and repair materials in a repair process,

- equipped with dedicated repair manuals in conditions of combat operations, and with special repair kits.

The especially significant element seems to be the modularity of assemblies together with the unification of parts, devices, and vehicles. The fulfilment of this parameter results in an easier and more available repair practice, as well as in adapting practices and repair kits to the whole family of vehicles or armoured fighting vehicles.

\section{Proactive Diagnostics}

Maintenance based on technical conditions was gaining importance in the past decades with the expansion of technical diagnostics. It is especially preventive in maintenance comprising of monitoring performance or parameters and of 
consequential measures. Its main benefit resides in consistent removal of failures. Particular worn parts and parts or whole assemblies in the risk of failure are repaired or replaced optimally in advance. Thus, failure occurrence is prevented.

Proactive maintenance is considered another higher level of maintenance. It is completely based on the previous predictive maintenance which it further improves, so that its basis is the utilization of more complex technical diagnostics. Basically it is the top current version of predictive maintenance based upon the actual condition of the item operated. It is analysed in detail in the following chapter.

Proactive maintenance arose from the predictive maintenance type as especially a reaction to long-term findings that a certain group of failures repeats periodically upon clear causes. Known causes include mainly the following:

- Incorrectly organised maintenance work.

- Incorrectly performed maintenance (technical operation in the vehicle).

- Unqualified operators and maintenance personnel.

The proactive maintenance type is aimed at keeping inherent reliability of the vehicle at an acceptable level. As a source of information, technical diagnostics is utilized. The main objective of proactive maintenance is:

- Further reduction of maintenance and operational costs.

- Prevention of failure occurrence and thus extension of an interval to preventive maintenance, meaning extension of the vehicle's durability.

- Statistic control of accidental and systematic influences affecting the vehicle operability [5].

An important feature of the ER system is information about fault occurrence given as soon as possible. Knowledge of size and place of damage, as well as its impact on the further operation of military equipment, has a direct influence on further actions that aim at restoring the equipment's efficiency.

The modern military vehicles use the civilian technology based on the CAN (Controller Area Network) bus for data transmission. However, for the needs of NATO armies, the MilCAN system was created in 1999 dedicated to the newest and the most advanced armoured fighting vehicles manufactured in NATO states. MilCAN is a deterministic protocol in which the CAN bus can be used in the technology determined by the ISO 11898 standard. Although this protocol was developed initially for the management 
system of the modern battlefield, the MilCAN is applicable wherever there is a requirement for deterministic data transfer.

An example of such a solution is the battlefield management system PBISA (Platform Battlefield Information System Application) used in the British Challenger II tanks, and a part of this system is a component of armoured fighting vehicle deck diagnostics (Fig. 1). Information generated by this component facilitates early detection and identification of faults; moreover, this information is of special importance for the temporary repair system.

\section{PBISA Equipment}
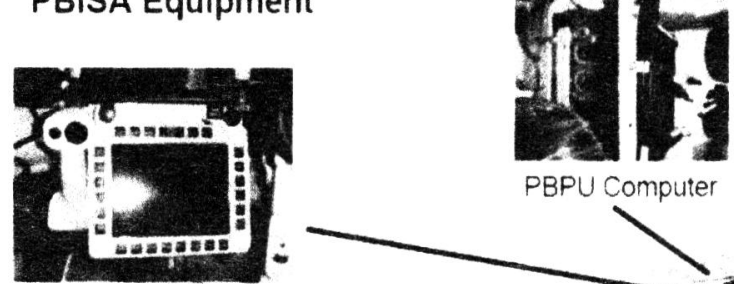

PBPU Computer

Commander s Pointing Device

Commander's Display

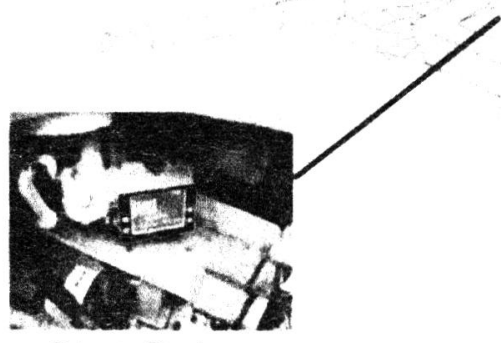

Driver s Display
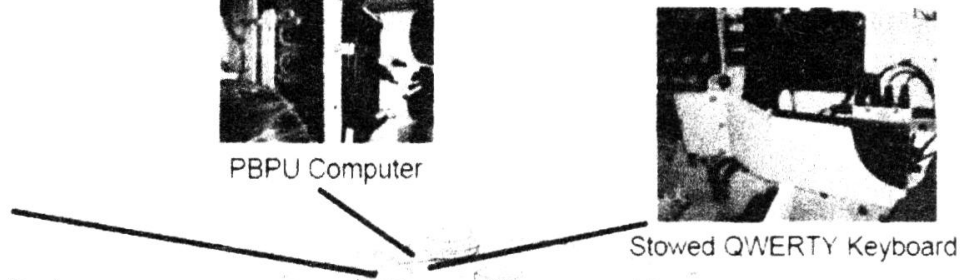

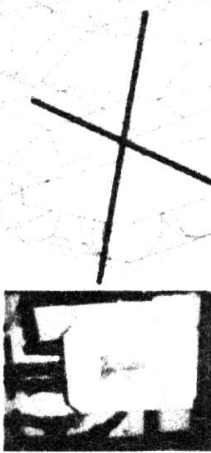

MilCAN USB Node

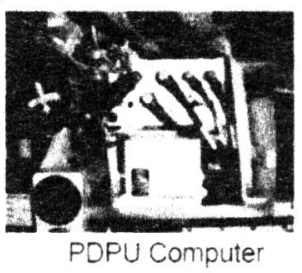

Inertia: Reference Uni:

Figure 1. Components of battlefield management system of Challenger II tank [6]

The final element in the deck diagnostics system is its diagnostics interface. Military vehicles compatible with the OBD II/EOBD (On Board Diagnostic II/ European On Board Diagnostics) system have got a unified diagnostics interface in order to provide easier data transfer and a possibility to interpret fault codes by different scanners and other data-reading devices. An example of a Polish armoured fighting vehicle equipped with the deck diagnostics system is the AMV Rosomak, whose system is compatible with OBD II/EOBD. 
The latest trend in the maintenance area is so called "telemaintenance", which may be explained as remote- controlled maintenance employing the proactive maintenance principle. In some publications, the term "Remote Diagnostics \& Maintenance (RD\&M)" is used [5]. It is based on the wireless transmission of technical data about the vehicle. The main field of its utilization is in companies specializing in long-distance transportation and also in the military environment. This method enables on-line monitoring of parameters upon sensors integrated in the vehicle and the wireless transmission of the information to a remote computer. This is very helpful especially for securing missions on a foreign territory.

Telemaintenance may be divided into the following four levels:

1. Diagnosed vehicle with a driver.

2. Support logistics centre where computer processed diagnostic information is located.

3. Experts performing the maintenance on the vehicle.

4. Vehicle manufacturer who supplies a technical database including drawings and technological procedures for maintenance [5].

Figure 2 shows a schematic telemaintenance system based on the wireless transmission of diagnosed data from the vehicle to the telemaintenance logistics centre and to the vehicle user. The vehicle electronic control unit makes performance indicators and error codes accessible for analysis; these are sent to the logistics centre. There, in the case of error messages an advisor informs the driver about the problem severity and advises on possible problem removal or provides necessary service support.

It means that the advisor ensures the vehicle maintenance or field repair with the use of a mobile workshop, or arranges maintenance in the maintenance and repair centre. If necessary, the logistics centre communicates further with the vehicle manufacturer who supplies the centre with new data materials for particular vehicle types. 


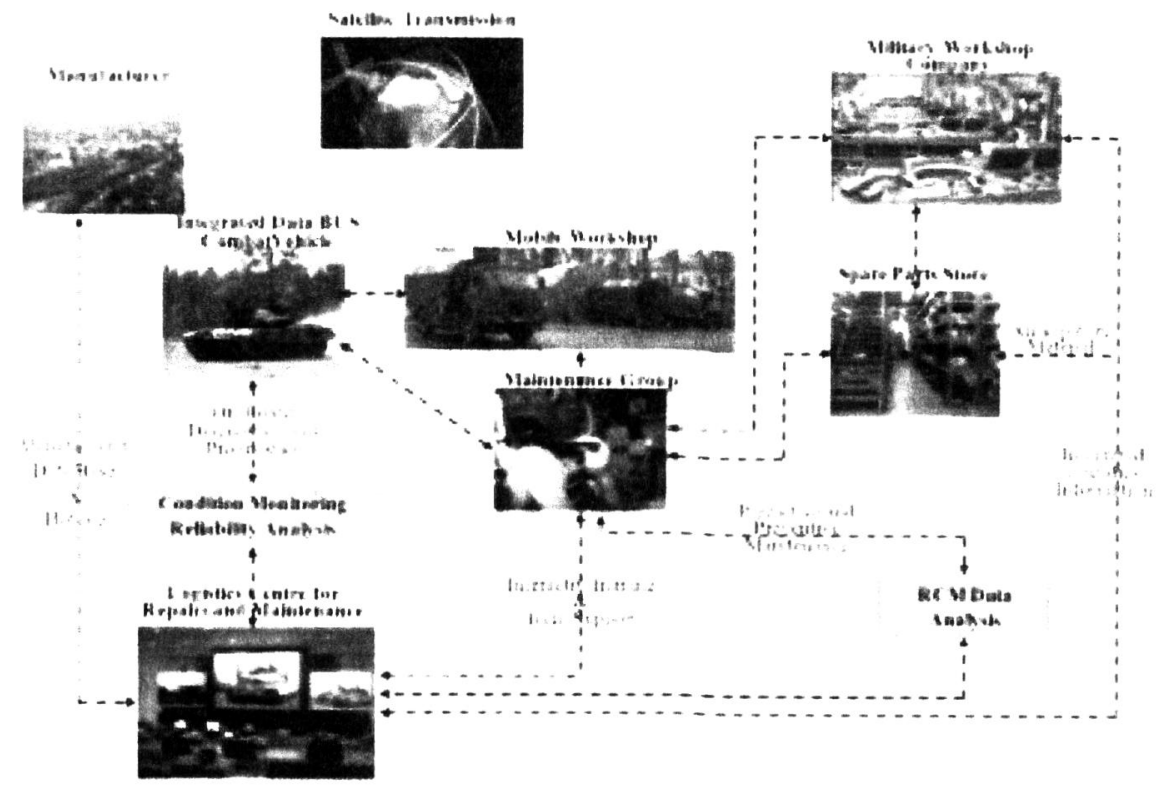

Figure 2. Design of telemetry maintenance system in battlefield [5]

\section{Design of a Container Mobile Workshop}

\section{General description of a container mobile workshop}

Determination of a container mobile workshop

A wheeled container workshop (a functional module) along with a special tool store is designed for repair levels 2 and 3, namely:

- the chassis of the car model range Tatra $(815,810)$,

- the chassis of the automobiles Land Rover etc.,

- the chassis of the wheeled armoured vehicles PANDUR II, Dingo and Iveco.

A tracked container workshop (a functional module) along with a special tool store is designed for repair levels 2 and 3, namely:

- the tracked combat vehicles BVP and T-72 M4CZ. 
The crew structure and the technical skills of the crew members are selected according to the types of supported combat vehicles and can change. For this workshop we recommend a 6-member crew consisting of a crew leader - an auto mechanic - a welder, a senior auto mechanic, an auto mechanic - a welder, a senior mechanic, a senior auto electrician, and a senior electrician [7], [8].

Standardized workshop solution

The container workshop is made from two pieces of ISO 1C size special containers arranged in an L shape (Fig. 3).
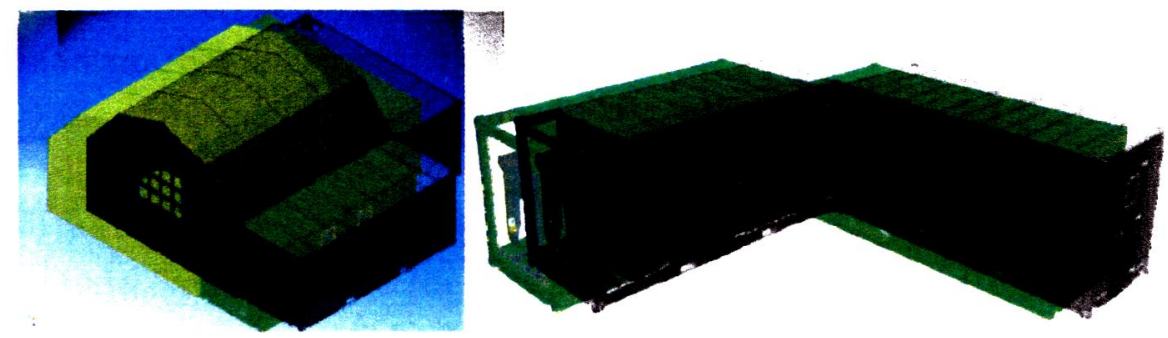

Figure 3. A container workshop project arranged in an L shape

The workshop consists of two container workshops. First the workplace is created with the working module which is universal for the maintenance of tracked and wheeled combat vehicles. The working module is placed in one ISO 1C container and is heat insulated with sandwich panels. The second workplace is created with the functional module then might be used for the maintenance and the repair of wheeled combat vehicles as well as tracked combat vehicles depending on internal facilities which might be changed according to the kind of supported vehicles. In the ISO IC container there is a special tools ì store which is actually a functional module equipped according to the kind of supported combat vehicles. The tools might be combined, where appropriate. In certain situations the module can be equipped with extra tools used for the maintenance and repair of armaments, communication equipment, etc. An outdoor workplace intended for the repair of land combat vehicles is designed with a roof which might be rolled out in the space between the containers, see Fig. 3 . 
The body of containers will be welded using steel sections and trapezoidal metal plates which will make a covering for the containers. The upper and bottom corner container elements of ISO 1C size will be built into basic bodies. The container panels themselves (peripheral and roof ones) will be filled with $40 \mathrm{~mm}$ thick insulating sandwich panels made of Elastopor SH 226/003 polyurethane foam which has been authorized for use in the Army of the Czech Republic after long-term tests. As for the covering material of insulating panels, it will bea $0,8 \mathrm{~mm}$ thick surface-modified aluminium plate.

A container floor will be made from isothermal floor panels with plywood, and covered with anti-slip PVC. The floor panels will be filled with the same Elastopor SH 226/03 polyurethane foam. The floor panels will be $50 \mathrm{~mm}$ thick. Entry doors to the containers will be equipped with a special door lock with the possibility to be locked by locks, and rigid clips for sealing.

The general external dimensions of $1 \mathrm{C}$ container are standardised. The mass of projected workshop modules will be as follows [7], [8]:

1. A working module
a) service weight $3000 \mathrm{~kg}$,
b) effective weight. up to $16500 \mathrm{~kg}$,
c) total weight. $19500 \mathrm{~kg}$.

2. A special tools store-a functional module
a) service weight
$2730 \mathrm{~kg}$,
b) effective weight. up to $22000 \mathrm{~kg}$,
c) total weight $24730 \mathrm{~kg}$.

\section{The workshops can be used for work [7], [8]:}

a) in mild climate zones, i.e.

- in the areas of average monthly temperatures from $-15^{\circ} \mathrm{C}$ to $25^{\circ} \mathrm{C}$,

- with the lowest temperatures rarely below $-32{ }^{\circ} \mathrm{C}$, and the highest rarely above $44^{\circ} \mathrm{C}$,

- with extreme temperatures of $-40^{\circ} \mathrm{C}$ and $50^{\circ} \mathrm{C}$,

b) with relative air humidity up to $90 \%$ and a temperature of $33^{\circ} \mathrm{C}$,

c) with air dustiness up to $1,5 \mathrm{~g} \cdot \mathrm{m}^{-3}$ taken $0,5 \mathrm{~m}$ above the ground level, 
d) with the speed of air flow up to $20 \mathrm{~m} \cdot \mathrm{s}^{-1}$,

e) with atmospheric precipitation such as rain, snow and hail,

f) at above sea level up to $3000 \mathrm{~m}$ (up to $4000 \mathrm{~m}$ for a short time).

\section{Providing that fuel supplies are big enough to allow for:}

a) heating operation for 48 hours,

b) power source function for 20 hours,

c) hot-air heating operation in a workshop tent for 10 hours.

The requirements regarding the work in a workshop are as follows:

a) the concentration of harmful substances will not exceed during 12-hour work $20 \mathrm{mg} / \mathrm{m}^{3}$ of carbon monoxide, $200 \mathrm{mg} / \mathrm{m}^{3}$ of oil fumes, $70 \mathrm{mg} / \mathrm{m}^{3}$ of petrol fumes, and $0,3 \mathrm{mg} / \mathrm{m}^{3}$ of sulphuric acid fumes,

b) there will be provided natural light as well as artificial light in the workshop,

c) the workshop will be equipped with lamps for main, spare, local and cover illumination according to the ĆSVN 83960 ,

d) the illumination level will be at least $50 \mathrm{Lx}$ in the check points $1 \mathrm{~m}$ off the ground and $0,5 \mathrm{~m}$ off the wall. The most illuminated place to the least illuminated place ratio will be bigger than 1 to 3 ,

e) the illumination of the workplace in a tent will be provided with a $230 \mathrm{~V}$ portable illuminating set with a screening slide.

For concealing the container workshop a camouflage net of $12 \times 15 \mathrm{~m}$ is used with supporting components and needles. In order to fasten a camouflage cover, the containers are on the sides equipped with clips for supporting components holding stability against wind. It takes approximately 20 minutes to conceal the container, and 15 minutes to remove the camouflage.

\section{The equipment of a working module and a functional module}

The equipment of a working module designed for the maintenance of wheeled and tracked combat vehicles

Working module was divided into two basic rooms (Fig. 4): 
1. Sealed (work-related) - is the main room for a functional workplace where work might be done.

2. Non-sealed (technological) - is the room intended for placing basic technological equipment consisting of the filter and ventilation plant FVZ 98, the air handler $\mathrm{K} 4 \mathrm{~A}$, the independent hot air heating D5LC, sources and electric and light distribution [7], [8].

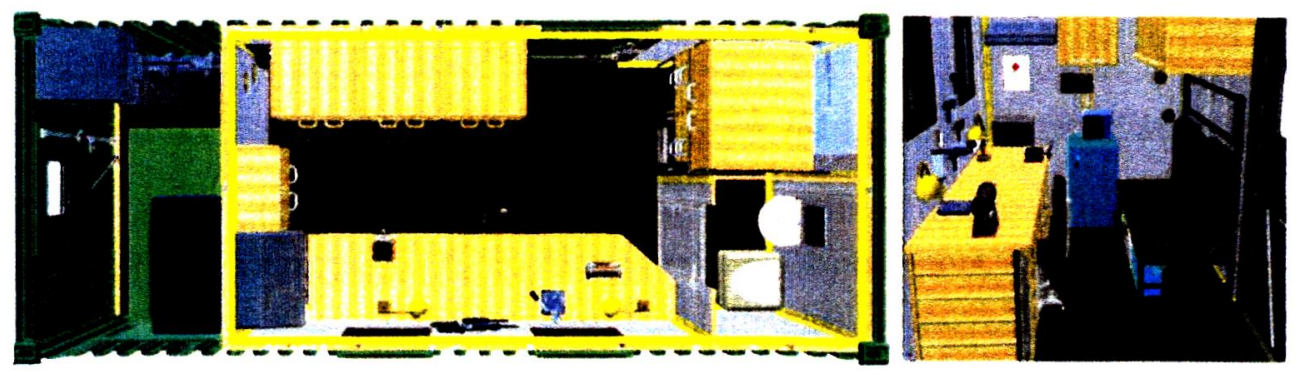

Figure 4. Top view of a working module designed for the maintenance of land combat vehicles

The equipment and main parameters of a functional module designed for the maintenance of wheeled or tracked combat vehicles

In the functional module we suggest putting the equipment used for welding by a welding arc, and charging accumulator batteries; a set for gas welding ( 1 acetylene bottle, 2 oxygen bottles, a bottle trolley, a welder set); a tent fly; portable oil firing; drive-up ramps, crane facilities (suspension tools), a hydraulic jack for 8 tons and 25 tons; expendable supplies and selected spare parts.

Apart from that, there is in the functional module a hydraulic swing crane placed at the front wall of the container to the left of an entry door. It is fixed on a special traversing bridge. The extending out and retracting of the crane is done by a linear hydraulic motor connected to the crane's hydraulic circuit. Two linear hydraulic motors providing the stability of the crane in a protruded position, they are also will be connected to the hydraulic circuit [7], [8]. 


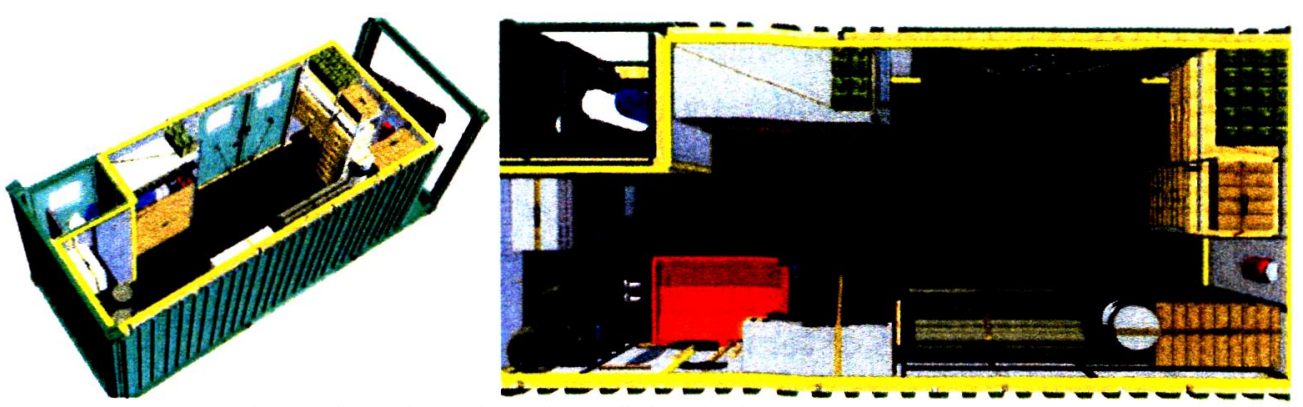

Figure 5. Top view of a functional module designed for the maintenance of land combat vehicles

In the functional module it is advisable to place also a set of coupling and suspension tools used for manipulating the systems and subsystems of the supplied technical equipment when dismantling and assembling vehicles. The tools are chosen from the unified set introduced within the Army of the Czech Republic.

In the mobile container workshop we suggest putting also the sets of battle damage repairs kits such as: metallurgical material, connection accessories, electrodes for electric arc welding, welding material for flame welding, soldering process, adhesives materials and materials used for repairing tire tubes and tires.

\section{Principles of Temporary Repairs}

According to Alliance documents „temporary repair is repair, which may be temporary, to restore equipment to a specified condition by non-conventional/improvised repair, both deployed and in-barracks, bounded by legal constraints" [9]. Similar formulation of the problem was presented in European Standard EN 13306 [10] where it is said that temporary was defined as: „physical actions taken to allow a faulty item to perform its required function for a limited time interval and until a repair is carried out". In the past the temporary repairs of military combat vehicles proceeded spontaneously and depended on the circumstances to be dealt with. The repair progress was influenced by experiences, the level of combat 
vehicle complexity, technical facilities and individual skills. Applying a different technology, using a reproduction part, or performing a repair by a serviceman without the competence are typical features of temporary repairs.

\section{Theoretical principles of temporary repairs}

It is good to realize that the temporary repair of combat vehicles cannot adequately substitute the repair performed in compliance with technical conditions and that is the reason why the next repair should be carried out in the shortest time frame. The reason for performing a regular repair is that a nonstandard procedure does not provide for dependability. In spite of all drawbacks, temporary repairs can play an important part in a combat operation.

\section{a) Temporary repairs in peace time}

The aim of a temporary repair in peace time is to renew or partly renew mobility and to prevent from more extensive damage, as for example environmental pollution caused by the leak of hazardous substances, safety threat by causing trouble in operation, or the devaluation of a transported material.

Operating costs are not expected to be increased due to the temporary repair, therefore, when deciding whether to perform it, the economical factor will be the main criterion. The economical factor can be expressed by the following formula [11]

$$
N_{O}+N_{(X)}+N_{Z(I)} \leq N_{O}+N_{Z(O)}
$$

where $N_{O}$ - the costs of performing the repair, $N D O$ - the temporary repair costs, $N_{Z t D O}$ - the loss incurred by the time the temporary repair is performed, and $\mathrm{NZtO}$ - the loss incurred by the time the repair is performed.

The loss can include the costs of the settlement of a possible breakdown, the devaluation of a transported material, penalty payments, repair assistance, the costs of reloading material, the recovery and evacuation of a vehicle, or the increased costs of the repair due to damage caused by performing the temporary repair. After modifying the equation (1), we get [11]

$$
N_{(X)} \leq N_{Z(O)}-N_{Z(D)()}
$$


which is an economical requirement for performing the temporary repair. However, even the much higher costs of performing the temporary repair as compared with the repair costs might be justified in this way, therefore the following formula must apply simultaneously

$$
N_{D O} \leq N_{O}
$$

and then it holds

$$
\left(N_{D O} \leq N_{Z T O}-N_{Z I D O}\right) \cap\left(N_{D O} \leq N_{O}\right) .
$$

When deciding whether to perform the temporary repair, we should take into account not only the costs, but also the fact of what extent a vehicle or a workshop vehicle is equipped with tools and material, to what degree a vehicle can be adapted to temporary repair performance, and the level of operating personnel skills.

Another important factor used when we are to agree on performing the temporary repair is time $t_{\text {min }}$, during which it is necessary to assure the main function of a temporarily repaired part until a regular repair is performed. The information stated above is followed by a requirement limiting the costs of temporary repair performance

$$
N_{D O} \leq t_{\min } \begin{gathered}
N_{Z t O}-N_{Z I D O} \\
\mathrm{~d} t
\end{gathered}
$$

Therefore, when deciding whether to perform the temporary repair in peace time, it holds [11]

$$
\left(N_{D O} \leq N_{O}\right) \cap\left(N_{D O} \leq t_{\min } \begin{array}{c}
\left.N_{Z t O}-N_{Z I D O}\right) . \\
\mathrm{d} t
\end{array}\right.
$$

\section{b) Temporary repairs in field conditions}

The difference between the temporary repair of combat vehicles performed in peace time and in field conditions is that we follow not only economical factors which are the most important in peace time, but also the provision of combat vehicle main functions, e.g. a weapon system, vehicle mobility and communication. The survival time of a vehicle (a crew) in a battlefield is crucial for deciding whether to perform the temporary repair. To put it simply, the recovery process of combat vehicle fighting power might be viewed as a geometric sequence [11]: 


$$
n_{t}=n_{0} q^{t-1}
$$

where $\mathrm{n}_{0}$ is the number of combat vehicles before the operation began, $\mathrm{n}_{\mathrm{t}}$ is the number of combat vehicles at the beginning of the day $\mathrm{t}, \mathrm{q}$ is a sequence quotient, $\mathrm{t}$ - the number of days.

The magnitude of the sequence quotient q can be described as the ability to repair damaged combat vehicles with the extension of loss $\mathrm{z}$, combat vehicle repairability $\psi$, and when considering the capacity and technical possibility of performing the repair with repair units $\varepsilon$.

Therefore

$$
q=1-z+\psi \varepsilon z
$$

Then, sustainability time is given by a decrease in the number of combat vehicles at an acceptable level $\mathrm{n}_{\mathbf{X}}$

$$
n_{x}=n_{0} \cdot q^{t_{x}-1}
$$

and therefore

$$
t_{x}=\frac{\log n_{x}-\log n_{0}}{\log q}+1
$$

when reaching the time $t_{\mathbf{x}}$ a unit must be replaced or supplied by another combat vehicle [11].

Performing temporary repairs helps to increase the capacity of repair units by labour saving, overcoming downtime due to the lack of spare parts, or involving crews in the repair process. This will be manifested in the rise in the coefficient value $\varepsilon$.

Graph 1 shows the courses of the decrease in fighting power with average of $20 \%$ daily losses $\mathrm{z}$, the limit of $55 \%$ fighting power and different magnitudes of $\psi$ and $\varepsilon$.

The courses of single curves show that extending the capacity of repair units has a positive impact on the fighting power time of supplied units, e.g. when performing temporary repairs. 


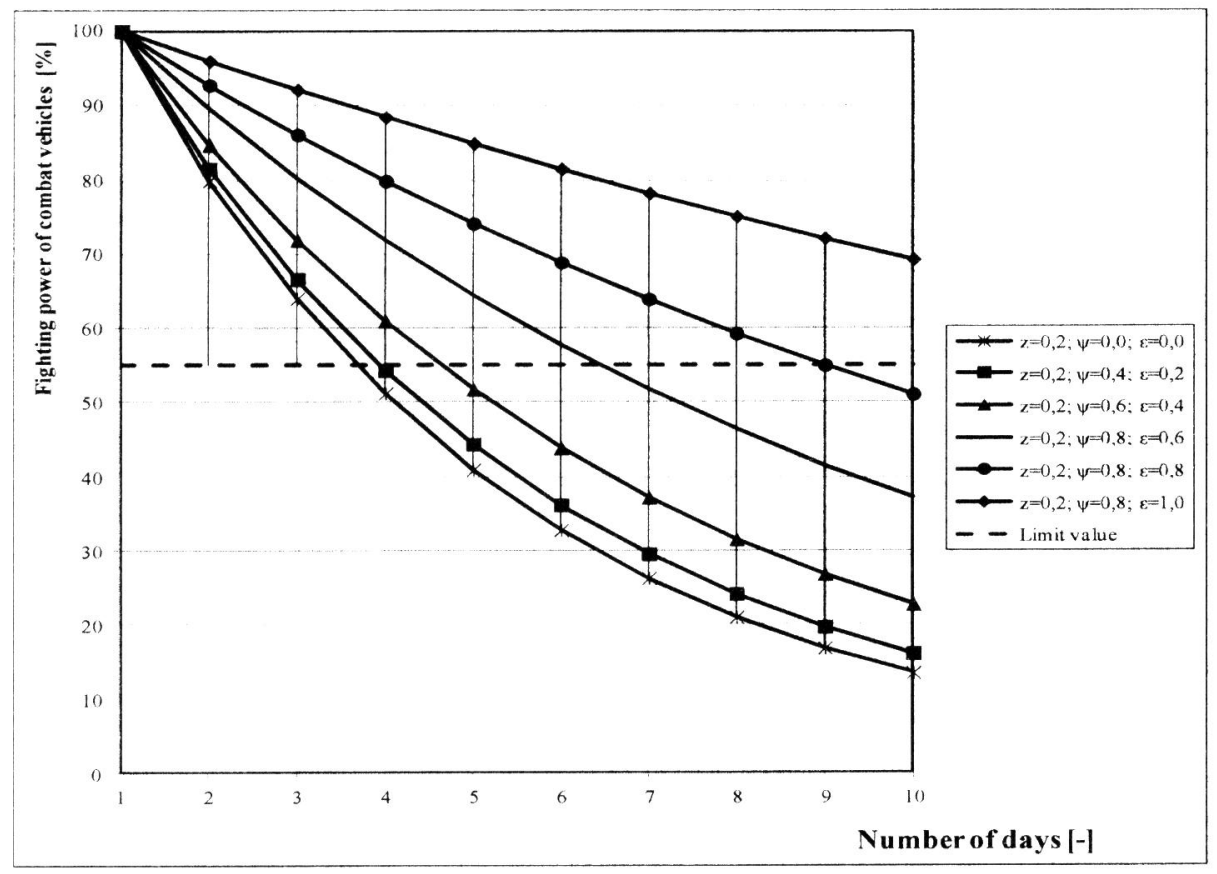

Graph 1. Fighting power of combat vehicles with $20 \%$ daily losses

\section{Temporary repairs technology}

The aim of a temporary repair system is to increase the level of professional personnel and workshop specialist readiness for the recovery of combat vehicle fighting capacity and to prepare the means of logistic support to provide this repair.

The system takes into account the development and verification of technologies which can be used for performing temporary repairs including their material support. The temporary repair system should be targeted, at well-arranged, technological procedures focused on the temporary repairs of important nodes with labour input time evaluation, necessary tools and material [11], [12].

We suggest that general procedures are to be subdivided per systems or parts common for combat vehicles. In the text below there is a division scheme and the possibilities of performing temporary repairs [11]. 


\section{Tanks}

- smaller ruptures and leaks which might be fixed by bandaging or cementing with the use of fast-setting two-part sealants,

- disruptive breakdowns which might be repaired through a combination of bandages and packing, or packing made of different material,

- damaged tanks which might be replaced by connecting barrels, canisters or heat resistant cases capable of being closed with a specific medium.

\section{Condensers}

- leakage which can be stopped using substances added to a cooling liquid which solidify during the leak from a cooling system, or fast-setting sealants used in the place of the leakage or nearby,

- disruptive breakdown which can be fixed by squeezing a tube with pliers and then filling the hole with a sealant or hot lead,

- damaged condenser which can be isolated for a short time and a cooling system might be interconnected without the condenser, or the condenser may be replaced by another part, e.g. a barrel or a demountable fuel tank.

\section{Pipe}

- minor damage and the leak of a low-pressure pipe which might be repaired by bandaging or using two-part workable sealants,

- more serious damage to a low-pressure pipe (not including exhaust pipes) which can be solved by replacing a damaged part with a rubber hose fastened with a sleeve or a band,

- damage to a high-pressure pipe which can be mended by pipe's offset and cementing the ends with anaerobic sealants, or by completely replacing the pipe using a high-pressure hose with endings.

\section{Air and hydraulic systems}

- damage to the part of a system which might be disabled by the blanking of a particular part, or providing a by- pass around a damaged part using hoses with endings. 


\section{Rods and shafts}

- cracked rods can be joined by a thicker bond sheet metal, the ends of which will be drilled and screwed together, or there will be used a sleeve welded at the end,

- cracked shafts will be joined by welding to a sleeve where applicable.

\section{Windings}

- minor damage can be mended by using a threaded coupling with an anaerobic sealant,

- damaged internal thread might be fixed by drilling off and using threaded insets which renew the original winding.

\section{Electric cables}

- visible local damage might be repaired using insulation with both ends twisted and insulated by an insulation tape, or the joint is welded,

- damage difficult to detect can be fixed by bridging a proper circuit using a new cable, or, in the case of power supply, by connecting with a cable assembly with nominal voltage.

\section{The design of a Battle Damage Repair Kit of Land Combat Vehicles in Field Conditions}

Repairs of land vehicles under field conditions are not only accomplished by using the mobile workshops but also by the use of temporary repairs. A similar formulation of the problem was presented in European Standard [10], where it is said that temporary repair is defined as: „physical actions taken to allow a faulty item to perform its required function for a limited time interval and until a repair is carried out".

We proposed the implementation of a battle damage repair (BDR) kit (Fig. 6) for the temporary repairs in the Czech Army. The dimensions of a BDR kit bag are $50 \times 32 \times 15 \mathrm{~cm}$ and its weight is $8.1 \mathrm{~kg}$. The bag is divided in to three separate boxes, in which the material for the temporary repairs of the land vehicles is placed. The 
first box contains adhesives and cements. There are tubes, adapters, connectors and plugs in the second box. In the third box there is material for repairs of the land vehicles electrical systems, for instance shielding, wire, crimping pliers, tin solder etc.
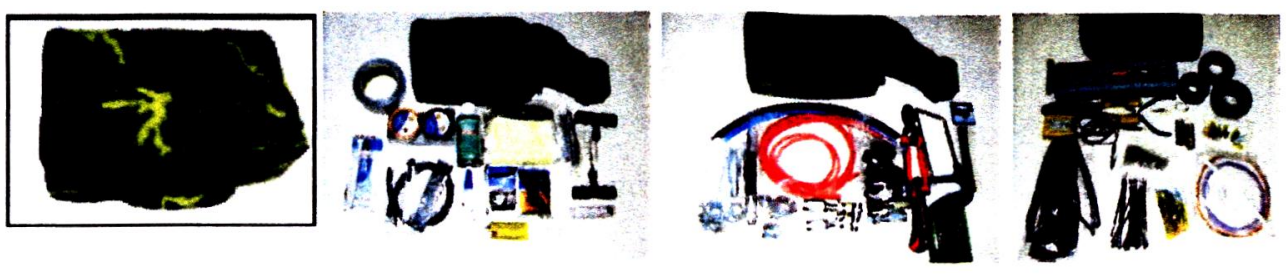

Figure 6. Battle damage repair kit for repair land combat vehicles

\section{Conclusions}

This paper presents the project of the container workplace designed for the maintenance of wheeled and tracked combat vehicles in field conditions. The quick and cheap replacement of functional module equipment according to the type of supplied technical vehicles is one of the advantages of this project. With replacing internal facilities, the wheeled version module might be changed into the tracked one and vice versa. Using a unified workplace module for the maintenance of both wheeled and tracked combat vehicles is another advantage of the project. The real benefit of the project lies in achieving unification and reducing the number of mobile workshops within the Army of the Czech Republic, because at present there are about 80 kinds of them.

The analysis conducted within the framework of the paper concerning possibilities and needs' analysis in a scope of armed systems' temporary repairs' implementation allows for the formulation of the following conclusions:

- The military equipment temporary repairs executed directly in the operation area can be a significant source of retrieving damaged military technology and has a direct influence on the combat ability of forces.

- Armed systems' survivability and field repairs should be formed already at the stage of equipment designing and manufacturing. 
- Procedural conditionings are essential with regard to executing repairs directly in operational areas. Equipment operation and instruction procedures must precisely determine the possibilities of using temporary repairs in the particular circumstances, which can ultimately contribute to further damage but still, it enables the unit to complete a task or even to save human life on the spot.

- To implement temporary repair system effectively, a trained and experienced staff, having proper equipment and repair materials, is essential.

\section{References}

[1] BRZEZIŃSKI, M. Military Logistics (In Polish). Warszawa: Bellona 2005. 127 p.

[2] DWORECKI, S. and KĘSOŃ, T. Armed Conflicts in Europe and Middle East (In Polish). Warszawa: Ministry of Defense 1996. 181-182 p.

[3] WÓCIK, J. The organization of repairs and technical evacuation according to ALP-9(B) Doctrine (In Polish). Zeszyty Naukowe WSO im. T. Kościuszki Poglądy i Dosìiadczenia, 2001, no. 4. p. 61-64. ISSN 1230-5243.

[4] SMAL, T. and SZUKALSKI, M. Logistic susceptibility of military equipment (In Polish). Logistyka, 2009, no. 6, on the included CD. ISSN 1231-5478.

[5] FURCH, J. New Trends in a Vehicle Maintenance System. Advances in Military Technology, 2010, vol. 5, no. 2, p. 1-9. ISSN 1802-2308.

[6] Available from: <http://www.milcan.org > [cited 2010.09.12].

[7] Furch, J., Těšík, O., Glos, J. a Marek, J.: Container workshop for tracked techniques repairs. ISBN 978-80-8040-356-0. Liptovský Mikuláš: Akadémia ozbrojených síl generála M.R. Štefánika, 2008, p. 175-182.

[8] Furch, J., Smal, T.: Design of container workplace for performing maintenance land combat vehicles in field conditions. ISSN 1731-8157. Wroclaw: Wydawnictvo Wyszej Szkoly Oficerskiej. 2011. Nr 3(161), p. 323 - 333.

[9] STANAG 2418 MC CSS (BM) (Edition 2), Procedures of expedient repairs, including battle damage repair. 2009.

[10] ČSN EN 13306:2002, Maintenance terminology.

[11] FURCH, J. and TĚŠÍK, O. Temporary Repairs of Army Vehicles (in Czech). In Proceedings of Armamant and Technics of Land Forces. Liptovský Mikulás: Akadémia ozbrojených síl generála M. R. Štefánika, 2006, p. 260-267.

[12] SMAL T. Modern organisational and technical solutions with regard to maintaining technical objects in usable conditions (In Polish), Zeszyty Naukowe WSOWL, 2010, no 4, p. 243-254. ISSN 1731-8157. 